\title{
Simultaneous existence of acute myeloid leukemia and chronic lymphocytic leukemia: a case report
}

\author{
Eman Al Mussaed ${ }^{1}$, Hani Osman² and Ghaleb Elyamany ${ }^{3^{*}}$
}

\begin{abstract}
Background: The simultaneous Occurrence of chronic lymphocytic leukemia (CLL) and acute myeloid leukemia (AML) has been rarely reported. Most of these cases have been occurring more frequently as a secondary event in patients receiving chemotherapeutic agents for CLL.

Case presentation: We describe a case of a 77-year-old man who presented with fatigue, pallor and lower limb pain and weakness. Initial laboratory studies showed Hb $7.7 \mathrm{~g} / \mathrm{dl}$, WBC $279.6 \times 10^{9} / 1$, PLT $143 \times 10^{9} / 1$. The peripheral blood (PB) smear examination showed circulating blast cells (20\%) cells and $50 \%$ lymphocytes, with smudge cells. A bone marrow examination showed infiltration by two discrete abnormal cell populations, one represents the leukemic blast cells (60\%) and the other represents small mature lymphocytes (30\%). The immunologic phenotype of blasts was characterized by the co-expression of CD13, CD33, CD14, CD4, CD15, CD64, HLA-DR, CD11c. Lymphocytes were characterized by a typical CLL immunophenotype: CD19+, CD5+, CD23+, CD20+ (dim) and negative for FMC7, CD34, CD10 and TdT. Cytogenetic studies were negative for CLL and AML panels. PCR assays for AML specific genetic abnormalities were negative. Immunoglobulin gene analysis established the clonal nature of the B-cell expansion. A final diagnosis of concomitant CLL and AML(FAB: M5) was made.
\end{abstract}

Conclusion: We have reported a case in which there was simultaneous presentation of AML and CLL. Both forms of leukemia were well documented by morphology, cytometric analysis and molecular studies. Our findings support the idea that this rare concurrence of AML and untreated CLL may represent two separate disease processes.

Keywords: Chronic lymphocytic leukemia, Acute myeloid leukemia, Case rep,

\section{Background}

The association of different malignancies with chronic lymphocytic leukemia (CLL) such as lung and skin cancer has been reported [1-5]. The coexistence of acute myeloid leukemia (AML) and CLL in the same patient has been occasionally reported. Most of these cases have been reported to occur after treatment of CLL with cytotoxic drugs suggesting that AML may be a secondary leukemia [3, 6-8]. Cases in the absence of prior treatment are exceedingly rare. Only a minority of reports represent de novo AML following untreated CLL or concomitant AML and CLL appearing as two distinct and unrelated malignancies [4, 6, 9-12].

\footnotetext{
*Correspondence: ghalebelyamany@yahoo.com

${ }^{3}$ Department of Central Military Laboratory and Blood Bank, Prince Sultan Military Medical City, PO Box 7897, Riyadh 11159, Kingdom of Saudi Arabia Full list of author information is available at the end of the article
}

We report a case of concomitant CLL and AML (FAB: M5) without previous exposure to a cytotoxic agent or irradiation. Morphologic features, flow cytometric analysis, molecular and cytogenetic findings of peripheral blood and Bone marrow samples are discussed.

\section{Case presentation}

A 77 year-old man presented with 3 weeks history of fatigue, pallor and lower limb pain and weakness with no history of previous exposure to a cytotoxic agent, irradiation or other medications except for hypertension. There was no history of fever, night sweats, weight loss, anorexia, chest pain, headache, blurring of vision or other relevant symptoms.

Physical examination was significant for enlarged spleen ( $3 \mathrm{~cm}$ below the costal margin), but no lymphadenopathy, hepatomegaly, jaundice or gum hypertrophy. Chest X-ray 
was normaland a computerized tomography (CT) scan revealed no lymphoadenopathies.

Initial PB count and smears showed anemia, thrombocytopenia, and leukocytosis (hemoglobin: $7.7 \mathrm{~g} /$ $\mathrm{dl}$, white blood cells $(\mathrm{WBC}) 279.6 \times 10^{9} / 1$, platelets $45 \times$ $10^{9} / 1$ ) with two distinct abnormal populations, the small cells were corresponding to mature lymphocytes (60\%) and large cells which corresponded to blast cells (20\%), and smear cells were also present (Fig. 1).

The immunophenotypic analysis, performed on $\mathrm{PB}$ and bone marrow (BM) aspirate samples confirmed the morphological findings of the presence of two abnormal malignant populations. The diagnosis of CLL was confirmed by demonstration of expression of mature B-cell markers (CD19, CD22, CD20 dim), the co-expression of CD5 and CD23 and the absence of immaturemarkers, such as CD34, Terminal deoxynucleotidyltransferase (TdT) and CD10. Similarly, the diagnosis of AML (FABM5) was confirmed by demonstration of expression of myeloid markers (CD13, CD15, CD33, HLA-DR, MPO) and monocytic markers (CD4, CD11c, CD14, CD64) and positive for CD38 and CD56 but negative for CD34 and CD117 (Fig. 2).

The BM was hypercellular with a diffuse pattern of infiltration by intermixed lymphocytes and blasts similar to those observed in the PB (Fig. 3). The lymphocytes comprised approximately $30 \%$ of the cellularity. Immunohistochemical staining for lymphocytes was positive for CD5, CD79a (not shown) and CD23 (not shown), negative for CD3 (Fig. 4). The blasts had monoblastic features, comprised approximately $60 \%$ of BM cells and showed positivity byimmunohistochemistry (IHC) for MPO, CD43 (Fig. 5) and negative for CD3 and CD79a. The final diagnosis was reported as co-existence of CLL and AML with monoblastic features (FAB-M5).

On the basis of clinical features and $C B C$ findings, the patient was started on hydroxyurea $1 \mathrm{~g}$ three times a day, Allopurinol and intravenoushydration to prevent tumor lysis syndrome. His white blood cell count showed dramatic response within 7 days of treatment within the normal range $\left(9.1 \times 10^{9} / \mathrm{L}\right)$, Hydroxyurea was subsequently discontinued.

Later on, the kidney function tests started to deteriorate and allopurinol was changed to Rasburicase. He developed acute on top of chronic kidney disease and he was started on peritoneal dialysis.

Conventional cytogenetic analysis was performed on metaphase cells prepared from BM specimen cultured for 24 and $72 \mathrm{~h}$ without mitogens, using standard techniques. The result was reported as a normal karyotype male [46, XY]. Fluorescence in situ hybridization (FISH) analysis was performed for common abnormalities associated with CLL and AML according to the manufacturer's instructions. FISH analysis for CLL was performed using the following probes panel: TP53/CEP17, D13S319/13q34, IGH/CCND1 (DC,DF), IGH/BCL2 (DC,DF) whereas FISH analysis for AML was performed using the following probes panel: AML-ETO (DC,DF)/

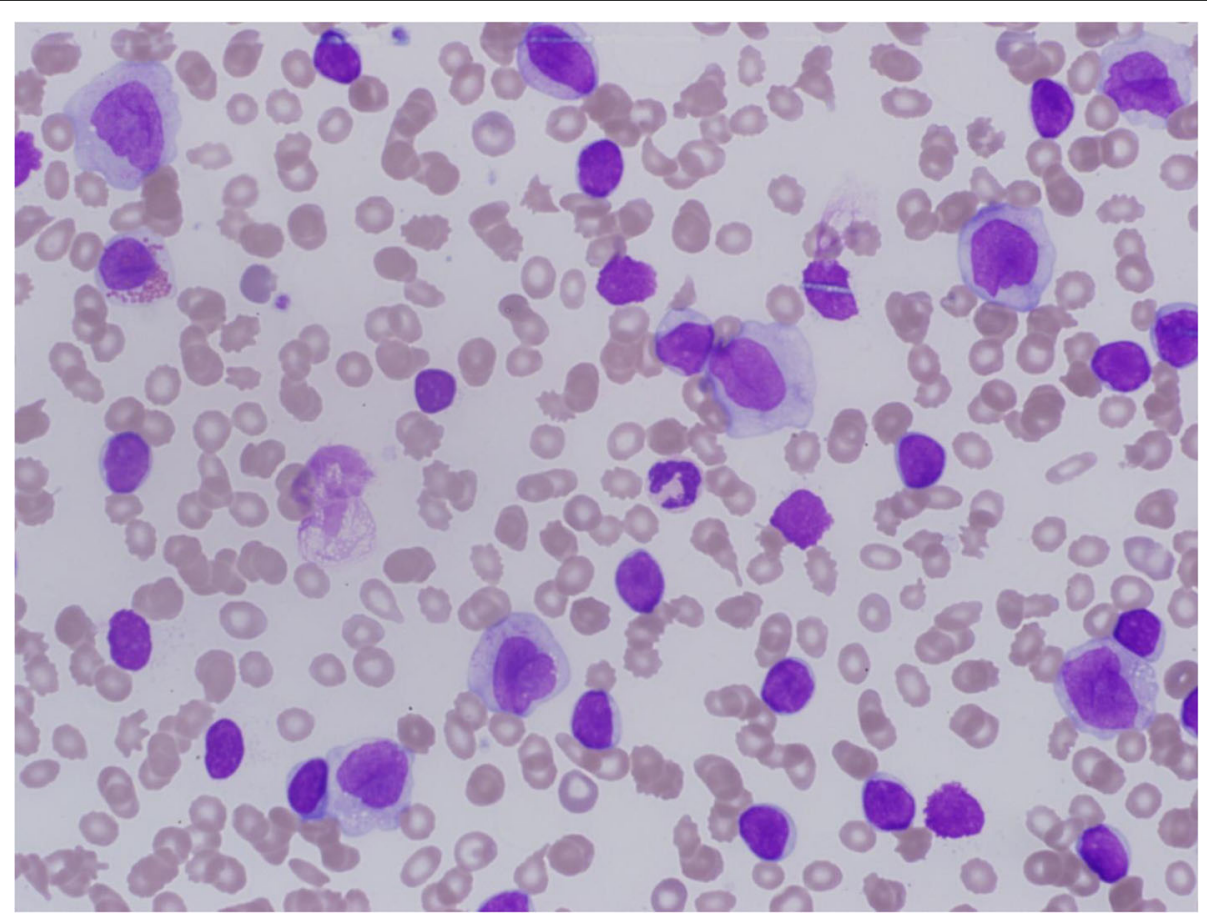

Fig. 1 PB smear showing circulating blast cells with monocytoid featuresand small mature looking lymphocytes with smudge cell 

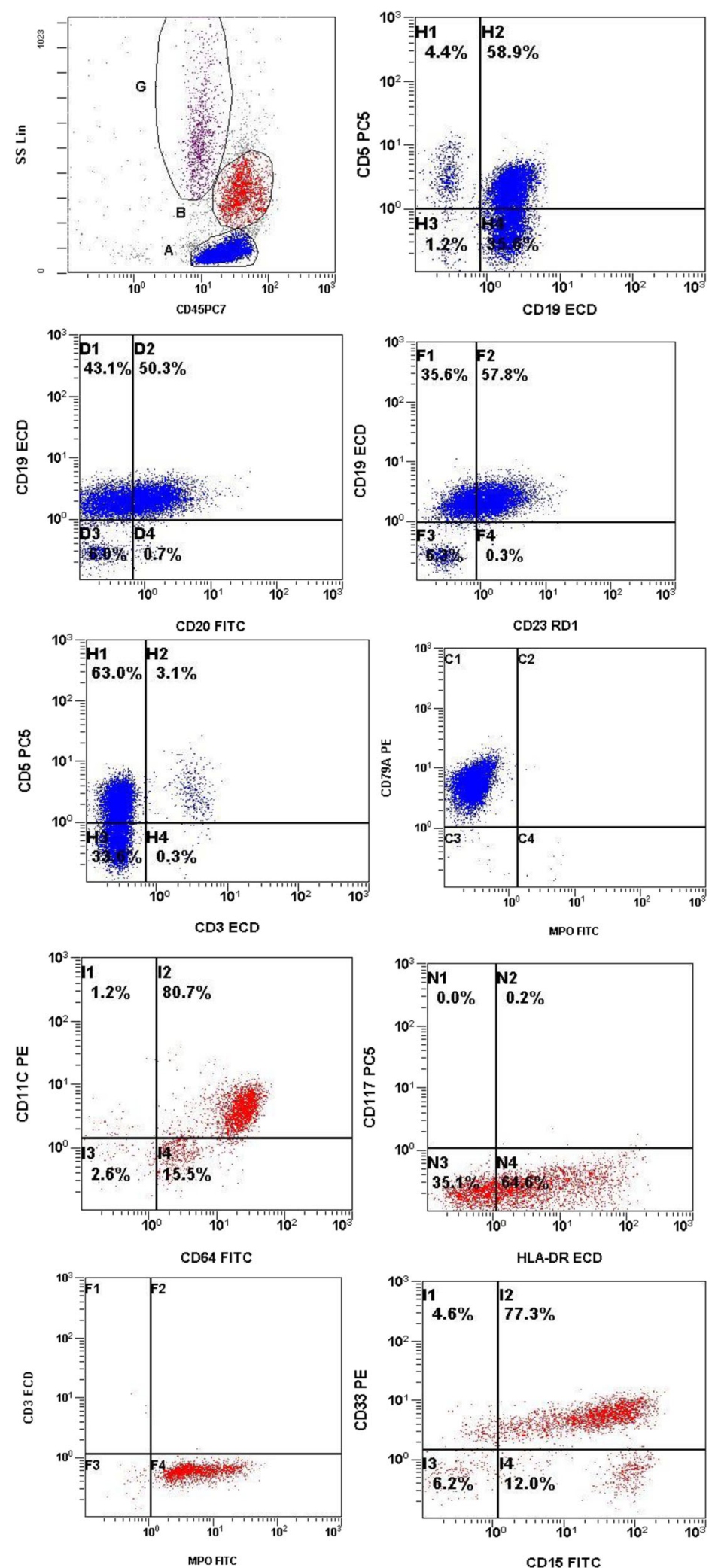

Fig. 2 Immunophenotyping on Peripheral Blood sample. Lymphocytes (blue color) were characterized by a typicall CLL immunophenotype: CD19 $+, \mathrm{CD} 5+, \mathrm{CD} 23+, \mathrm{CD} 20+(\mathrm{dim}), \mathrm{CD} 79 \mathrm{a}+$ and negative for CD3 whereas the immunologic phenotype of blasts (red color) was characterized by the co-expression of CD33, CD14, CD15, CD64, HLA-DR, CD11c and MPO 


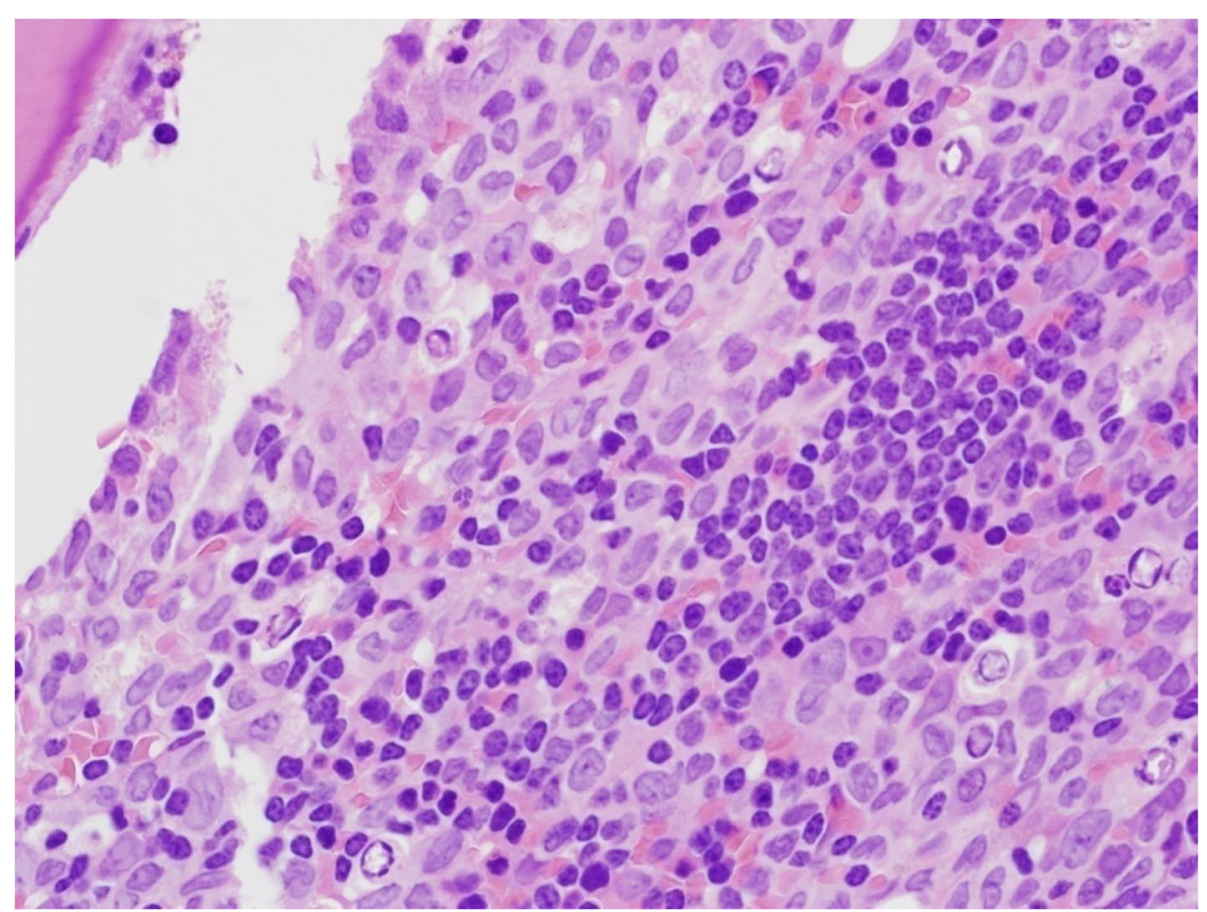

Fig. 3 BM trephine biopsy infiltration by two discrete abnormal cell populations, one represents the leukemic blast cells with monocytoid features and the other represents small mature lymphocytes

$\mathrm{t}(8 ; 21)(\mathrm{q} 22 ; \mathrm{q} 22)$, PML-RARA (DC,DF)/t(15;17)(q22;q21), CBFB (DC,BAR)/inv(16)(p13;q22), MLL (DC,BAR)/11q23 and CEP8/D8Z2. FISH results were negative for both CLL and AML panel- specific abnormalities. RNA isolated from the BM sample according to the manufacturer's instructions was subjected to reverse transcriptasepolymerase chain reaction (RT-PCR) using a nested PCR reaction, to ascertain the presence or absence of $\mathrm{AML}$ specific abnormalities mentioned before. Similarly, DND was extracted according to the manufacturer's instruction to detect both FLT3 gene mutations (ITD and D835) using published primers $[13,14]$ and reported negative for both AML specific abnormalities and FLT3 gene mutations. PCR amplifications of genomic DNA established the clonal nature of the B-cell expansion by the presence of the IgH gene rearrangement.

Due to old age, comorbid conditions and his performance status, the patient received palliative therapy with no curative treatment of his hematological malignancies. The patient died on the tenth day of hospitalization due to complications of both metabolic functions and infection.

The association of different malignancies with chronic lymphocytic leukemia has been reported. The most common second malignancies are solid tumors, especially lung and skin cancers [3]. The association of AML and CLL has been previously described. Most of these cases have been developed after treatment of CLL with chemotherapeutic agents suggesting that AML may be a secondary leukemia.
Both disorders have been occasionally diagnosed simultaneously in untreated patients, appearing as two distinct and unrelated malignancies [3, 4].

In the present case study, the $\mathrm{PB}$ and $\mathrm{BM}$ morphologic findings are of AML with monoblastic features. FCM and IHC data are also consistent with AML-M5 but in addition, flow cytometric studies detect the presence of a lymphoproliferative process, CLL (CD5+/CD19+). The association of AML and CLL has been previously described [4-6]. Cytogenetic and FISH studies performed on interphase cells revealed no cytogenetic abnormalities such as deletions in chromosomes 6q21, $11 \mathrm{q} 22,13 \mathrm{q} 14$, and $17 \mathrm{p} 13$, and trisomy $12(+12)$ which are usually detected in $60-80 \%$ of CLL patients $[15,16]$.

The history of the patient in the present study did not reveal any exposure to known leukemogenic agents or chemotherapy for CLL. The diagnoses of both AML and CLL were simultaneous, although we cannot rule out a previous asymptomatic indolent course of CLL. Although the simultaneous occurrence of AML and CLL is rare, it should not be overlooked as a possible cause of lymphocytosis in AML patients, as it has been reported that a reactive polyclonal lymphocytosis may occur in isolated cases of AML or, more commonly, in myelodysplastic syndrome patients [17].

Multiple theories behind the development of simultaneous malignancies in patients with CLL have been proposed [11]. The first theory involves immunosuppression 

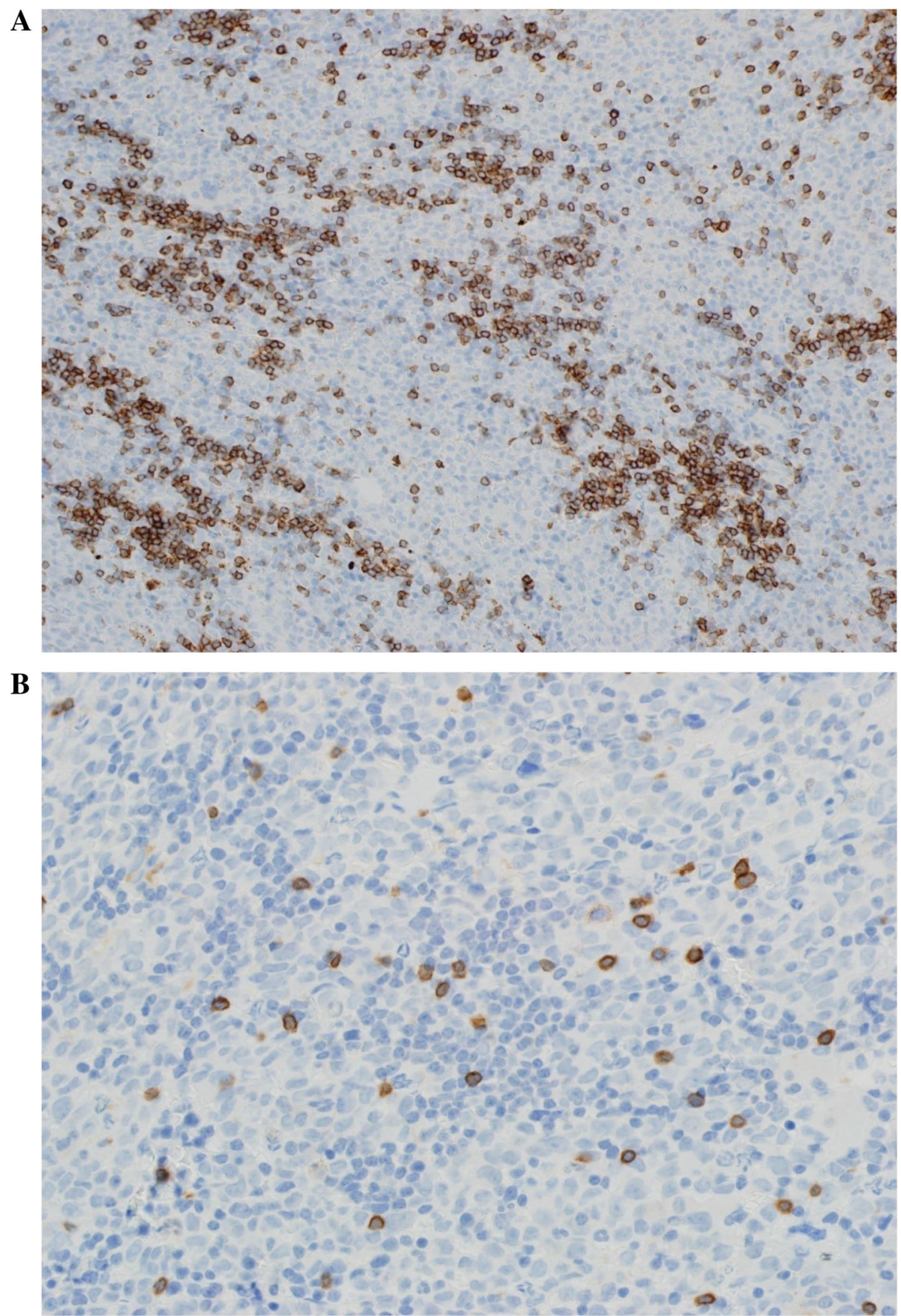

Fig. 4 Immunohistochemical staining forl ymphocytes was positive for CD5 (a) and negative for CD3 (b)

reported in these patients [18]. Some authors hypothesize that the simultaneous occurrence of AML and CLL may be due to a common stem cell defect or leukemogenic factors or possibly a genetic susceptibility in some patients [19]. However, concomitant AML and CLL occurring due to chance cannot be excluded [20]. In treatment-related cases, in addition to decreased immune competence, the cytotoxicity and DNA damage induced by chemotherapy are also contributing factors
$[1,5,21]$. However, others have demonstrated that the phenomenon results from separate karyotype abnormalities in the myeloid and lymphoid lines, triggering two separate neoplastic events $[6,11,22-24]$. Our findings support the idea that this rare concurrence of AML and untreated CLL may represent two separate disease processes as CLL arises from abnormal population of CD5+, CD19+ B lymphocytes whereas AML derives from an abnormal myeloid precursor. 


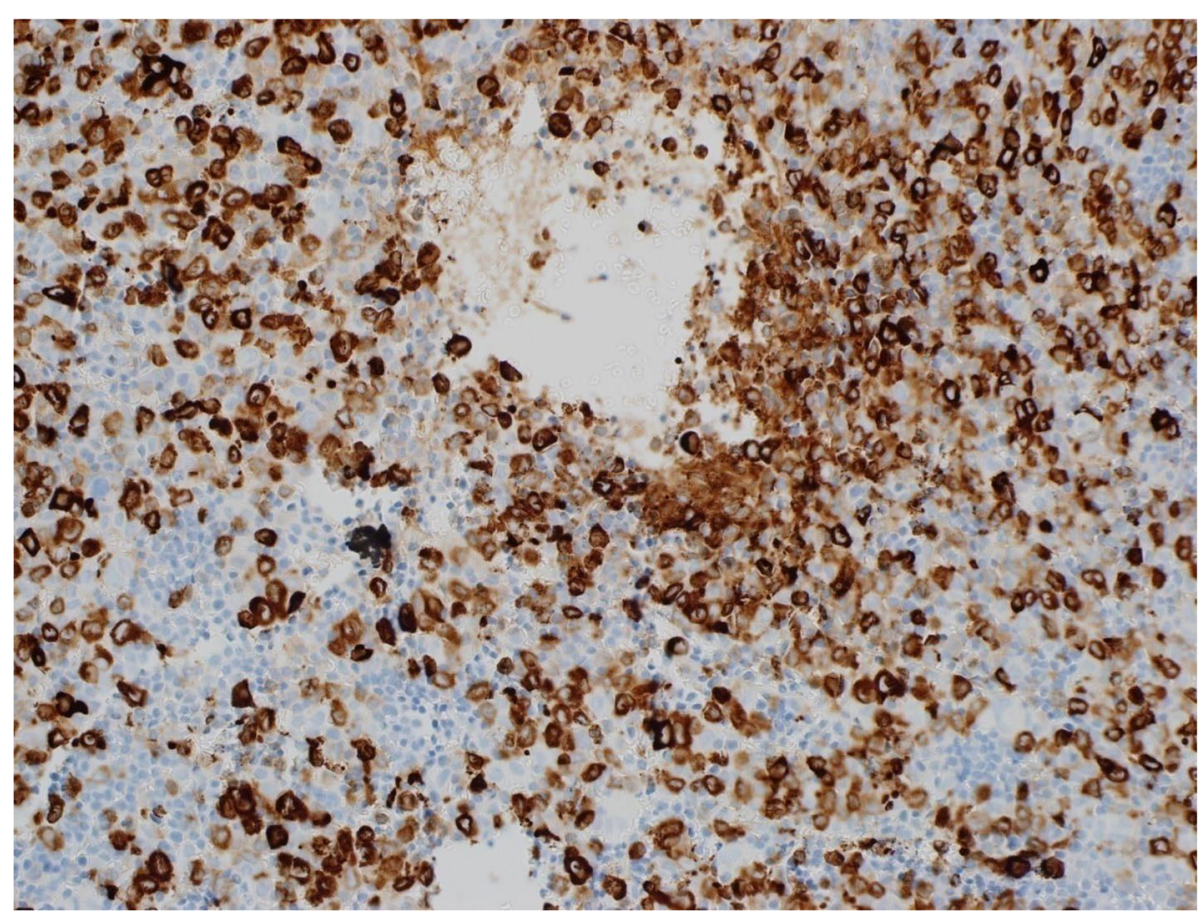

Fig. 5 Immunohistochemical staining for blast cells was positive for MPO

\section{Conclusions}

In summary, we have reported a case in which there was simultaneous presentation of AML and CLL. Both forms of leukemia were well documented by morphology, cytometric analysis and molecular studies. This increases the number of cases in which concomitant CLL and AML have been found without previous exposure to a cytotoxic agent or irradiation. Our findings support the idea that this rare concurrence of AML and untreated CLL may represent two separate disease processes.

\section{Abbreviations}

AML: Acute myeloid leukemia; BM: Bone marrow; CLL: Chronic lymphocytic leukemia; CT: Computerized tomography; FAB: French-American-British; PB: Peripheral blood; PCR: Polymerase chain reaction; TdT: Terminal deoxynucleotidyltransferase

\section{Acknowledgements}

We thank all the Hematology, Histopathology, Cytogenetic and Molecular Laboratories Staffs for data collection and technical help.

\section{Funding}

None.

\section{Availability of data and materials}

The data is publicly available or can be requested.

\section{Authors' contributions}

GE carried out the BM, flow cytometry studies and drafted the manuscript. EA, $\mathrm{HO}$ conceived of the study, and participated in its design and coordination and helped to draft the manuscript. All authors read and approved the final manuscript.

\section{Competing interest}

The authors indicated no potential conflicts of interest.

\section{Consent for publication}

Written informed consent was obtained for publication.

Ethics approval and consent to participate

This case study was approved by the Departmental Research and ethics committee of Department of Cental Military laboratory and Blood Bank.

\section{Author details}

'Department of Basic Sciences, Hematopathology Division, Princess Nourah Bint Abdulrahman University, College of Medicine, Riyadh, Saudi Arabia. ${ }^{2}$ Department of Adult Clinical Hematology and Stem cell Therapy, Prince Sultan Military Medical City, Riyadh, Kingdom of Saudi Arabia. ${ }^{3}$ Department of Central Military Laboratory and Blood Bank, Prince Sultan Military Medical City, PO Box 7897, Riyadh 11159, Kingdom of Saudi Arabia.

Received: 31 December 2015 Accepted: 14 September 2016 Published online: 19 September 2016

\section{References}

1. Molica S, Alberti A. Second neoplasms in chronic lymphocytic leukemia: Analysis of incidence as a function of the length of follow-up. Haematologica. 1989:74:481-5.

2. Bertoldero G, Scribano G, Podda L, et al. Occurrence of second neoplasm in chronic lymphocytic leukemia. Experience at Padua hospital between 1979 and 1991. Ann Hematol. 1994;69:195-8.

3. Meloni G, Proia A, Guerrisi V, et al. Acute myeloid leukemia and lung cancer occurring in a chronic lymphocytic leukemia patient treated with fludarabine and autologous peripheral blood stem-cell transplantation. Ann Oncol. 2000;11(11):1493-5.

4. Caballero MD, Gonzalez M, Canizo MC, et al. Concomitant Chronic Lymphocytic Leukemia (CLL) and Acute Myeloid Leukemia. Complete Remission of CLL Achieved with High-Dose Cytosine Arabinoside. Leukemia. 1992;6:856-8.

5. Conlan MG, Mosher DF. Concomitant Chronic Lymphocytic Leukemia, Acute Myeloid Leukemia, and Thrombosis with Protein C Deficiency. Cancer. 1989;63:1398-401.

6. Gottardi M, Valter G, Degan M, et al. Concomitant chronic lymphocytic leukemia andacute myeloid leukemia: Evidence of simultaneousexpansion of two independent clones. Leuk Lymphoma. 2006;47(5):885-9. 
7. Rund D, Ben-Yehuda D. Therapy-related leukemiaand MDS: evolving concepts of pathogenesisand treatment. Hematology. 2004;9:179-87.

8. Morrison VA, Rai KR, Peterson BL, et al. Therapy-Related Myeloid Leukemia Are Observed in Patients withChronic Lymphocytic Leukemia After Treatmentwith Fludarabine and Chlorambucil: Results of anlntergroup Study, Cancer and Leukemia Group B9011. Clin Onc. 2002;20(18):3878-84.

9. Stern N, Shemish J, Ramot B. Chronic lymphatic leukemiaterminating in acute myeloid leukemia: Review of the literature. Cancer. 1981;47:1849-51.

10. Dighiero G, Maloum K, Desablens B, et al. Chlorambucil inindolent chronic lymphocytic leukemia. N Engl J Med. 1998;338:1506-14.

11. De Filipp Z, Huynh DV, Fazal S, et al. Allogeneic stem cell transplantation foracute myeloid leukemia with del(7q) following untreated chronic lymphocytic leukemia. Hematol Oncol Stem Cell Ther. 2012;5(3):165-8.

12. Lai R, Arber DA, Brynes RK, et al. Untreated chronic lymphocytic leukemia concurrent with or followed by acute myelogenous leukemia or myelodysplastic syndrome. A report of five cases and review of the literature. Am J Clin Pathol. 1999;111:373-8.

13. Yamamoto $Y$, Kiyoi H, Nakano Y, et al. Activating mutation of D835 within the activation loop of FLT3 in human hematologic malignancies. Blood. 2001;97(8):2434-9.

14. Kiyoi H, Naoe T, Nakano Y, et al. Prognostic implication of FLT3 and N-RAS gene mutations in acute myeloid leukemia. Blood. 1999;93(9):3074-80.

15. Döhner H, Stilgenbauer S, Benner A, et al. Genomic aberrations and survival in chronic lymphocytic leukemia. N Engl J Med. 2000;343:1910-6.

16. Elyamany G, Fadalla K, Elghezal $H$, et al. Chronic Lymphocytic Leukemia with $\mathrm{t}(14 ; 18)(\mathrm{q} 32 ; \mathrm{q} 21)$ As a Sole Cytogenetic Abnormality. Clin Med Insights Pathol. 2014;7:21-7.

17. Rosenthal NS, Farhi DC. Reactive plasmacytosis and lymphocytosis in acute myeloid leukemia. Hematol Pathol. 1994;8:43-51.

18. Gómez-Arbonés J, Gallart MA, Mellado A, et al. Concomitant diagnosis of acute myeloid leukemia (AML) and chronic lymphocytic leukemia (CLL). Importance of flow cytometry in the diagnosis of CLL without lymphocytosis accompanying AML. Eur J Haematol. 1997;59(5):335-7.

19. Lima M, Porto B, Rodrigues $M$, et al. Cytogenetic Findings in a Patient Presenting Simultaneously with Chronic Lymphocytic Leukemia and AcuteMyeloid Leukemia. Cancer Genet Cytogenet. 1996;87:38-40.

20. Goldman JW, Goldman M, Louis J. Statistical approach to chronic lymphocytic leukemia and acute leukemia. Arch Intern Med. 1978;138:659.

21. Miller MK, Strauchen JA, Nichols KT, Phelps RG. Concurrent chronic lymphocytic leukemia cutis and acute myelogenous leukemia cutis in a patient with untreated CLL. Am J Dermatopathol. 2001;23(4):334-40.

22. Ornellas De Souza MH, de Souza FT, Diamond HR, et al. Cytogenetic and immunophenotypic evidence of independent clonal origins of concomitant chronic lymphocyticleukaemia and acute myeloid leukaemia. Eur J Haematol. 2001;66(4):281-3.

23. Katz JB, Curran AL, Zemba-Palko V, Dabrow MB, Denshaw-Burke MT. Synchronous Diagnosis of Chronic Lymphocytic Leukemia and Acute Myeloid Leukemia. J Clin Oncol. 2010;28(35):e726-8.

24. Fattizzo B, Radice T, Cattaneo D, Pomati M, Barcellini W, lurlo A. Three hematologic malignancies in the same patient: chronic lymphocytic leukemia, followed bychronic myeloid leukemia and acute myeloid leukemia. Clin Lab. 2014;60(11):1929-32.

\section{Submit your next manuscript to BioMed Central and we will help you at every step:}

- We accept pre-submission inquiries

- Our selector tool helps you to find the most relevant journal

- We provide round the clock customer support

- Convenient online submission

- Thorough peer review

- Inclusion in PubMed and all major indexing services

- Maximum visibility for your research

Submit your manuscript at www biomedcentral com/submit 